\title{
Simulation-Based Learning to Improve Athletic Trainers' Knowledge of Exertional Sudden Death Conditions: A Pilot Study
}

\author{
Zachary K. Winkelmann \\ University of South Carolina, winkelz@mailbox.sc.edu \\ Elizabeth R. Neil \\ Xavier University, beth.neil@temple.edu \\ Kenneth E. Games \\ Indiana State University, kenneth.games@indstate.edu \\ Stacy E. Walker \\ Ball State University, sewalker@bsu.edu \\ Lindsey E. Eberman \\ Indiana State University, lindsey.eberman@indstate.edu
}

Follow this and additional works at: https://nsuworks.nova.edu/ijahsp

Part of the Adult and Continuing Education Commons, and the Medical Education Commons

This Manuscript has supplementary content. View the full record on NSUWorks here: https://nsuworks.nova.edu/ijahsp/vol18/iss3/15

\section{Recommended Citation}

Winkelmann ZK, Neil ER, Games KE, Walker SE, Eberman LE. Simulation-Based Learning to Improve Athletic Trainers' Knowledge of Exertional Sudden Death Conditions: A Pilot Study. The Internet Journal of Allied Health Sciences and Practice. 2020 Jan 01;18(3), Article 15.

This Manuscript is brought to you for free and open access by the College of Health Care Sciences at NSUWorks. It has been accepted for inclusion in Internet Journal of Allied Health Sciences and Practice by an authorized editor of NSUWorks. For more information, please contact nsuworks@nova.edu. 


\title{
Simulation-Based Learning to Improve Athletic Trainers' Knowledge of Exertional Sudden Death Conditions: A Pilot Study
}

\begin{abstract}
Purpose: Continuing education for the practicing clinician typically involves reading peer-reviewed journals and attending professional conferences. These mechanisms do not allow for practice and real-time evaluation of healthcare skills. Simulation-based learning has been widely used in professional education yet is not common in the continued development of the clinician in their lifespan. Method: We used a crosssectional, repeated measures pilot study. The participants included 11 athletic trainers (age $=40 \pm 14$ years; certified experience $=17 \pm 14$ years) that engaged in a multi-modal continuing professional development session that included a lecture, large-scale simulated learning experience, and debriefing session at a healthcare conference. The outcome measures included 1) a 6-item effectiveness tool to assess the overall program, 2) pre, post, and 6-month follow-up knowledge assessments, and 3) a 6-month follow-up qualitative viewpoint statement. Results: The participants rated the program as effective and useful. On the knowledge assessment, the participants scored an average of $74 \%$ on the pre-test and $87 \%$ on the posttest with an average change score of a $20.5 \%$ increase following the educational session. We identified a significant improvement $(P=0.002)$ in the participants from pre-test to post-test, however a decay in the knowledge improvements from post-test to follow-up at six months $(P=0.188)$ was noted. Conclusion: A multi-modal educational intervention was effective at improving knowledge immediately following the session. This study offers promise that continuing education through simulation may improve knowledge acquisition while serving as a catalyst for clinical practice behavior change.
\end{abstract}

\section{Author Bio(s)}

Zachary K. Winkelmann, PhD, SCAT, ATC, is a Clinical Assistant Professor in the Arnold School of Public Health at University of South Carolina. He is also the Clinical Education Coordinator for the PostProfessional Athletic Training Program at University of South Carolina.

Elizabeth R. Neil, PhD, AT, ATC, is a Teaching Professor and Clinical Education Coordinator in the Sport Studies Department at Xavier University in Cincinnati, $\mathrm{OH}$.

Kenneth E. Games, PhD, LAT, ATC is an Associate Professor and Director of Clinical Education for the Doctor of Athletic Training Program in the Department of Applied Medicine and Rehabilitation at Indiana State University.

Stacy E. Walker, PhD, ATC, FNATA is a Professor in the School of Kinesiology at Ball State University in Muncie, IN. She is a Fellow from the National Athletic Trainers' Association and expert in simulation-based learning.

Lindsey E. Eberman, PhD, LAT, ATC is a Professor and Program Director for the Doctor of Athletic Training Program in the Department of Applied Medicine and Rehabilitation at Indiana State University. She is a certified and licensed athletic trainer.

\section{Acknowledgements}

The authors would like to thank Dr. Cameron J. Powden (University of Indianapolis) for his assistance in the project, as well as the Great Lakes Athletic Trainers Association for hosting the simulated-learning experience. 


\title{
IUAHSP \\ The Internet Joumnal of Allied Health Sciences and Practice \\ Dedicated to allied health professional practice and education \\ Vol. 18 No. 4 ISSN 1540-580X
}

\section{Simulation-Based Learning to Improve Athletic Trainers' Knowledge of Exertional Sudden Death Conditions: A Pilot Study}

\author{
Zachary K. Winklemann ${ }^{1}$ \\ Elizabeth R. Neil2 \\ Kenneth E. Games ${ }^{3}$ \\ Stacy E. Walker ${ }^{4}$ \\ Lindsey E. Eberman ${ }^{3}$
}

1. University of South Carolina

2. Xavier University

3. Indiana State University

4. Ball State University

United States

\begin{abstract}
Purpose: Continuing education for the practicing clinician typically involves reading peer-reviewed journals and attending professional conferences. These mechanisms do not allow for practice and real-time evaluation of healthcare skills. Simulationbased learning has been widely used in professional education yet is not common in the continued development of the clinician in their lifespan. Method: We used a cross-sectional, repeated measures pilot study. The participants included 11 athletic trainers (age $=40 \pm 14$ years; certified experience $=17 \pm 14$ years) that engaged in a multi-modal continuing professional development session that included a lecture, large-scale simulated learning experience, and debriefing session at a healthcare conference. The outcome measures included 1) a 6-item effectiveness tool to assess the overall program, 2) pre, post, and 6-month follow-up knowledge assessments, and 3) a 6-month follow-up qualitative viewpoint statement. Results: The participants rated the program as effective and useful. On the knowledge assessment, the participants scored an average of $74 \%$ on the pre-test and $87 \%$ on the post-test with an average change score of a $20.5 \%$ increase following the educational session. We identified a significant improvement $(P=0.002)$ in the participants from pre-test to post-test, however a decay in the knowledge improvements from post-test to followup at six months $(P=0.188)$ was noted. Conclusion: A multi-modal educational intervention was effective at improving knowledge immediately following the session. This study offers promise that continuing education through simulation may improve knowledge acquisition while serving as a catalyst for clinical practice behavior change.
\end{abstract}

Keywords: heat stroke, professional development, standardized patients 


\section{INTRODUCTION}

Approximately 9000 secondary school athletes suffer from exertional heat illnesses yearly, which has subsequently resulted in 61 deaths (51 secondary schools; 10 collegiate) of football players from 1995-2016. ${ }^{1,2}$ Although some heat illnesses, like exercise associated muscle cramps and heat exhaustion, are considered very common, they are not very severe. ${ }^{3}$ Exertional heat stroke, exertional rhabdomyolysis, exertional sickling, and exertional hyponatremia, however, have led to fatal outcomes when improperly diagnosed or treated. ${ }^{3,4}$

Although sudden death events with negative outcomes may be limited, many of the major, media-reported incidents have included multiple patients related to exertional heat illness or other sudden death conditions. ${ }^{5-11}$ These multi-patient trauma events, often characterized with several active patient situations, are commonly seen in marathon, triathlon, and endurance races, however there have been several reported cases of mass patient encounters in organized sport at the secondary school and college levels in football, soccer, and track. When multi-trauma patient situations occur, medical providers often sort and triage..$^{12,13}$ These mechanisms help to determine which patients require immediate care and their likelihood to survive pre-hospital management.

The National Athletic Trainers' Association has released position statements in 2012 and 2015 on Preventing Sudden Death in Sport and Exertional Heat IIInesses, but a growing body of work indicates that athletic trainers possess the cognitive knowledge to know what diagnostic criteria and interventions are necessary, yet they report not choosing those methods in their own clinical practice.3,4,14-16 Specifically, the literature has called for educational interventions related to rectal thermometers and cold water immersion. ${ }^{17,18} \mathrm{It}$ is possible that a lack of practice with these health care skills contributes to the disconnect between what the clinician knows and what they choose to do in patient care. Most of the standards related to the health care skills necessary to recognize or manage sudden death conditions like rectal thermometry, supplemental oxygen, and cold-water immersion were included in the $5^{\text {th }}$ edition of the National Athletic Trainers' Association athletic training educational competencies and the 2012 Commission on Accreditation of Athletic Training Education Standards for the Accreditation of Professional Athletic Training Programs. ${ }^{19,20}$ Thus, athletic trainers credentialed before 2013 may not have had education, specifically the knowledge, skills, and abilities required to implement these lifesaving skills. The lack of knowledge or lack of willingness to implement these skills has even more harmful effects when the athletic trainer is serving as a health care executive, or an individual that oversees and manages the quality of services provided at the point-of-care.

We propose the use of simulation to practice and implement optimal recognition, triage, and management strategies to resolve this practice gap..$^{3,4,21}$ Simulation-based training is a method that allows learners to engage in skill development in low-stakes situations. ${ }^{22}$ This method of training attempts to recreate characteristics of the real world. As a result, simulation experiences typically involve mannequins, standardized patients or patient actors, part-task trainers, and simulators. The use of simulation is not the addition of technology alone, but often incorporates several media including live actor portrayal that allow interaction of the clinician with the patient mimicking a real-life scenario. ${ }^{23}$

Previous research exploring educational interventions related to exertional heat illness identified attitude and perception improvements following a multi-phase session including a lecture, question-and-answer, and practical experience. ${ }^{24,25}$ However, the findings also indicate the translation of the knowledge into future clinical practice may not occur, as the attitudes and perceptions noted improved about expected behaviors, yet the long-term effectiveness of the intervention was not studied. ${ }^{24,25}$ Athletic trainers in a leadership capacity have a duty to ensure that high-quality care is provided to patients through their subordinates, and as such, their role also includes educating their staff about best practices but also assessing whether those best practices are implemented practically. Therefore, the purpose of this study was to evaluate the effectiveness of a simulated learning session and debrief on actual knowledge transfer among credentialed athletic trainers following a continuing education session and after returning to clinical practice.

\section{METHODS}

\section{Participants}

Participants were recruited from a convenience sample of athletic trainers who registered and attended the Board of Certification approved evidence-based practice (EBP) continuing education session titled, "Recognition and Management of Exertional Heat IIIness: A Simulated Learning Experience", that occurred during the Athletic Trainers' Association annual symposium in March of 2018. The learners attended one of the 3 continuing education sessions. The instruction and simulation were recreated for three separate sessions during the conference with up to 10 learners per session. All learners were provided a verbal explanation of the study and the electronic informed consent. Participation in the continuing education session was not contingent upon agreeing to participate; however, the components of the learning experience (including the pre-test and post-test for EBP credit) were required for completion of the continuing education session. In total, 24 learners attended the continuing education session with all completing the pre-test and post-test. However, only $11(46 \%)$ of the participants consented to share their test results for the 
purpose of this study. Moreover, all 11 participants (age $=40 \pm 14 \mathrm{y}$; certified experience $=17 \pm 14 \mathrm{y}$ ) agreed to participate in the six-month follow-up assessment with an opportunity to provide their personal accounts that occurred in September 2018. Participants included 6 females and 5 males that provided healthcare services in secondary schools $(n=6,54.5 \%)$, colleges $(n=3$, $27.3 \%$ ), or clinic/hospitals ( $n=2,18.2 \%)$.

\section{Instruments}

The study was comprised of two instruments including the actual knowledge assessment and the program effectiveness scale. The pre-test, post-test, and follow-up test were all conducted using the same tool via Qualtrics ${ }^{\circledR}$ (Provo, UT). The knowledge assessment included 21 items focused on three constructs including: recognition ( 9 items), triage (4 items), and management (8 items). The knowledge assessment was previously validated, and a pilot study of the knowledge assessment was conducted prior to the continuing education session with minor changes occurring to layout, wording, and content based on pilot participant feedback. To reduce pre-post-test recall, the question set for each of three constructs were randomized per participant at each of the data collection time points. Directions in the knowledge assessment asked the participant to complete the tool without referencing outside materials. The program effectiveness scale was included in the post-test assessment. The scale evaluated the learning experience and was required by the conference. The scale included six items measured on a 7-point Likert-scale from $1=$ strongly disagree to $7=$ strongly agree.

\section{Procedures}

The participants engaged in 90 minutes of instruction and simulation during the continuing education session. The research team delivered the lecture for about 30 minutes, a large-scale educational simulation for about 30 minutes, and a debriefing session of the experience for about 30 minutes. The instructional lecture provided via Microsoft PowerPoint served to refresh or advance the cognitive knowledge of the participants. The large-scale educational simulation was designed to force the participants to apply their knowledge to standardized patients. Health care simulation and standardized patients are best done when they mimic a real patient encounter and are developed by clinicians and educators together. ${ }^{26}$ We have developed a large-scale scenario that mimics that which occurred during the January 2011 hospitalization of University of lowa football players. ${ }^{27}$ In this case, the patients experienced two days of intense strength training followed by a speed conditioning workout with 13 patients eventually being diagnosed with exertional rhabdomyolysis. ${ }^{27}$ We replicated a multi-trauma case that combines cases of exertional rhabdomyolysis (three live patient actors), exertional heat stroke (one patient actor), and exertional sickling (one patient actor). The simulation required the learners to recognize and treat patients according to best-practice standards. In addition, several other "healthy" live patient actors seeking treatment in the athletic training facility also were present. The learning objectives of the large-scale simulation are referenced in Table 1. All patient actors were trained extensively using best-practice recommendations in the literature. ${ }^{28}$

Table 1. Learning Objectives for Participants

\begin{tabular}{|c|c|}
\hline$\bullet$ & Triage to determine if conditions, injuries, or illnesses are life threatening. \\
\hline & $\begin{array}{l}\text { Interpret signs and symptoms of injuries, illnesses, or other conditions that require referral, utilizing medical history } \\
\text { and physical examination to insure appropriate care }\end{array}$ \\
\hline & $\begin{array}{l}\text { Formulate a clinical diagnosis by interpreting history and the physical examination to determine the appropriate } \\
\text { course of action. }\end{array}$ \\
\hline • & Implement appropriate emergency and immediate care procedures to reduce the risk of morbidity and mortality \\
\hline - & Implement referral strategies to facilitate the timely transfer of care \\
\hline • & Administer therapeutic interventions for general medical conditions to aid recovery to optimal function. \\
\hline
\end{tabular}

Following a brief introduction to the large-scale simulation and expected procedures, the participants were allowed 3 minutes to familiarize themselves with the athletic training facility. Some of the participants were instructed to begin in the athletic training facility while others were directed throughout the conference center with walkie-talkies to mimic being out at various venues. The athletic training facility was created using supplies and tables in the conference hotel meeting space. The meeting space (35 feet x 32 feet) was divided into two distinct areas for the lecture and the simulated athletic training facility with room divider curtains. In addition, supplies relevant to the emergency patient care (cold water immersion submersion tub filled with Orbeez ${ }^{\circledR}$ water beads, rectal thermistor with enema trainer model, supplemental oxygen, pulse oximetry, etc.) and other general care items (foam roller, massage lotion, etc.) were present in the facility. Finally, a mock emergency action plan was created and posted with phone numbers for emergency medical services and access routes. Figure 1 provides images of the simulated athletic training facility. 


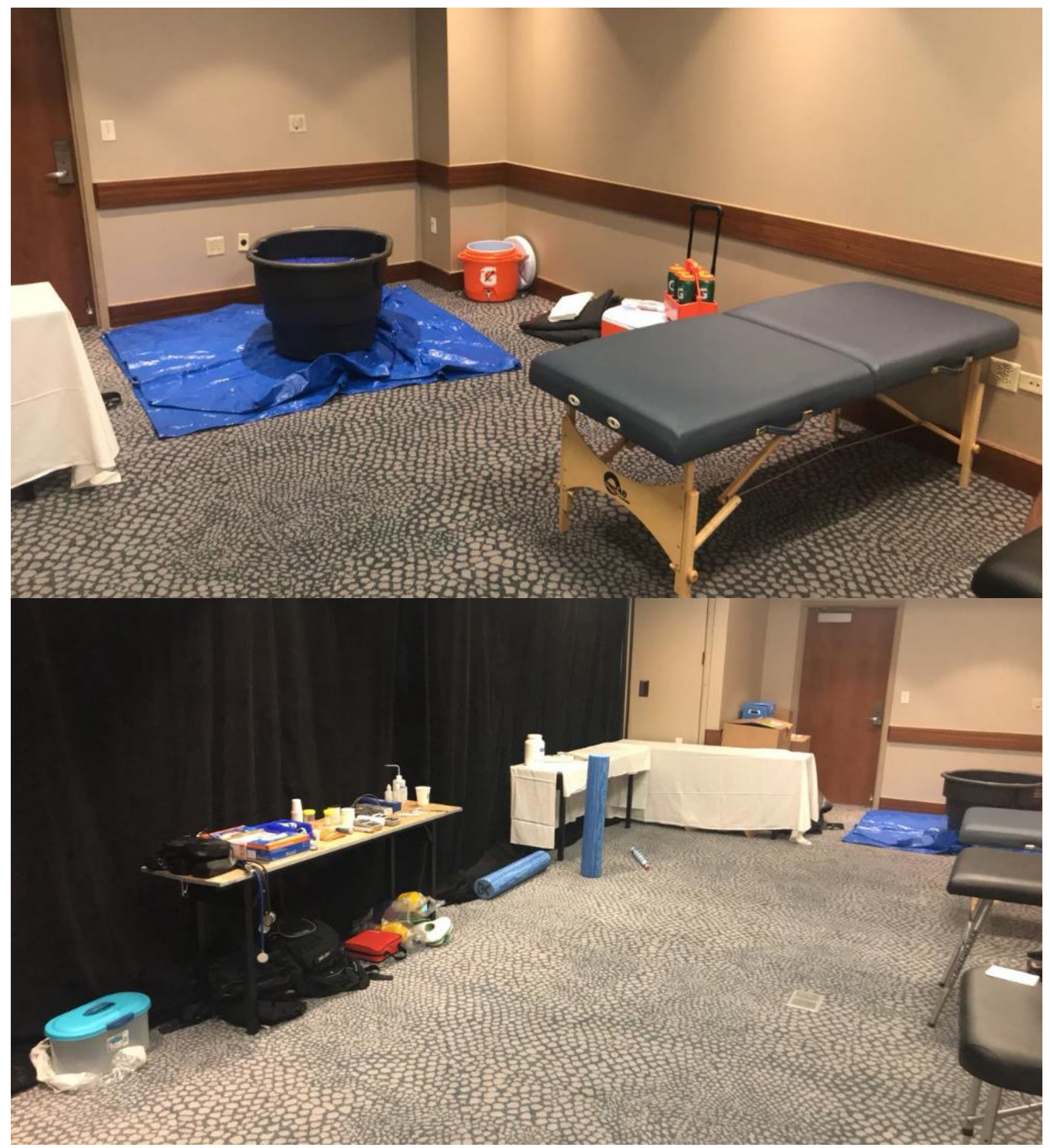

Figure 1. Simulated athletic training facility with emergency and non-emergency supplies.

After the introduction, the simulation began with one participant experiencing exertional rhabdomyolysis presenting to the athletic training facility, followed-by a second patient with exertional rhabdomyolysis presenting 2 minutes later, and then several "filler" live actors coming in for general treatment. Seven minutes into the simulation, a member of the track team in the hallway reports that their teammate has collapsed requiring the participants to remove themselves from the facility to take care of the third patient experiencing acute exertional heat stroke. Three minutes later (10 minutes into the simulation), the fourth patient with exertional rhabdomyolysis presents followed three minutes later with a patient acutely presenting with exertional sickling. The simulation was terminated at 30 minutes, highest priority patient transport being activated, and/or an unsafe learning experience occurring. Figure 2 provides an example of learners providing patient care during the large-scale simulation to the live patient actors. 


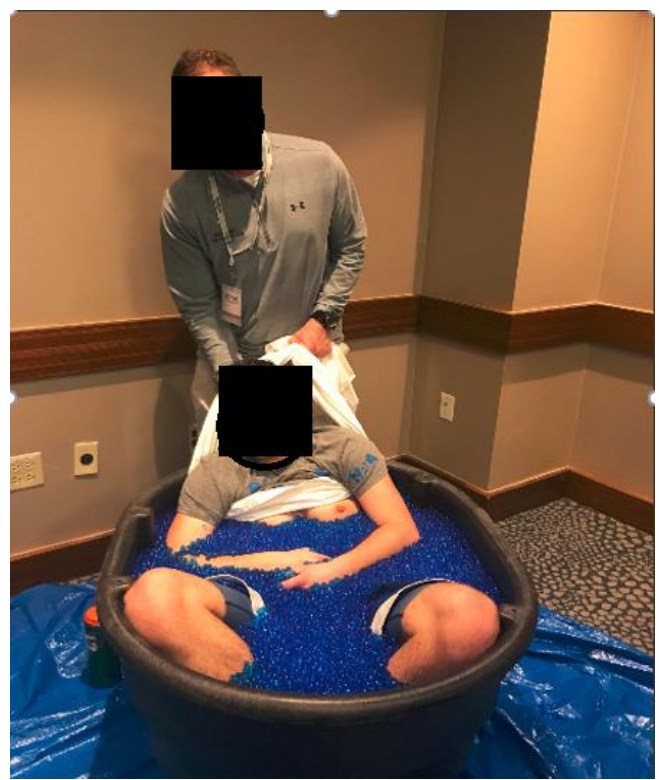

Figure 2. A learner oversees a patient during simulated cold-water immersion treatment

Following the cessation of the simulation, the participants engaged in a debriefing session with the research team and live actors. Debriefing is a crucial part of the simulation process and allows the learners to self-reflect with colleagues about the strengths and weaknesses of their performance in group format. ${ }^{29}$ Immediately following the debrief, the learners completed the post-test knowledge assessment. Anyone who chose to participate in the research was contacted six months later to complete the followup knowledge assessment. The study was approved for by the Indiana State University Institutional Review Board. Participant recruitment and data collection took place in March and September 2018 with data analysis occurring thereafter.

\section{Data Analysis}

The results were analyzed using SPSS (version 25; IBM Corp., Armonk, NY). Measures of central tendency were calculated for the program effectiveness scale. Correct response frequencies were calculated for each knowledge assessment question at pretest, post-test, and follow-up. A mean score on the knowledge assessment was calculated. Due to attrition and to accurately represent the data, we calculated three paired-samples t-tests to compare the test performances and calculated percentage change scores to demonstrate change for the sample. The alpha level was set at $P<0.01$ a priori.

\section{RESULTS}

\section{Program Effectiveness}

Of the 11 participants that agreed for us to use their data, they each rated the program as effective and useful. Table 2 provides data reflective that the participants rated between agree to strongly agree for each of the six items.

Table 2. Program Effectiveness ( $n=11)$

\begin{tabular}{|l|c|c|c|c|c|}
\hline \multicolumn{1}{|c|}{ Criteria } & Mean & SD & Min & Max & Mode \\
\hline $\begin{array}{l}\text { The program content was practical, useful, } \\
\text { comprehensive, appropriate, and in-depth. }\end{array}$ & 6.5 & 0.7 & 5.0 & 7.0 & 7.0 \\
\hline The program achieved its stated objectives. & 6.6 & 0.5 & 6.0 & 7.0 & 7.0 \\
\hline $\begin{array}{l}\text { The session utilized effective teaching and learning } \\
\text { methods. }\end{array}$ & 6.6 & 0.5 & 6.0 & 7.0 & 7.0 \\
\hline $\begin{array}{l}\text { The faculty were effective in the quality of the } \\
\text { instruction. }\end{array}$ & 6.7 & 0.5 & 6.0 & 7.0 & 7.0 \\
\hline The session included useful educational materials. & 6.7 & 0.5 & 6.0 & 7.0 & 7.0 \\
\hline $\begin{array}{l}\text { The program was appropriate and did not } \\
\text { demonstrate any bias. }\end{array}$ & 6.9 & 0.3 & 6.0 & 7.0 & 7.0 \\
\hline
\end{tabular}

Scale $=7$-point Likert Scale from 1=Strongly Disagree to 7=Strongly Agree; SD = standard deviation 


\section{Knowledge Assessment}

The knowledge assessment was scored out of 21 questions with the 11 participants scoring at $74 \%$ on the pre-test and at $87 \%$ at post-test. The average percentage change score for the participants was a $20.5 \%$ increase (minimum $=0 \%$, maximum $=63 \%$ ) following the educational intervention. Table 3 provides a breakdown of the frequency of correct responses for the pre-test, posttest, and follow-up knowledge assessment per question. We identified a significant improvement (mean difference $=2.82$ points; $P=0.002 ; 1-\beta=0.787 ; E S=1.22)$ in the participants from pre-test (mean $=15.5 \pm 2.5)$ to post-test (mean $=18.3 \pm 1.8$ ). At the sixmonth follow-up, attrition did occur with only 7 participants $(64 \%)$ completing the follow-up knowledge assessment. When exploring the long-term knowledge improvements of the participants, we identified that the participants did improve from pre-test (mean $=16.1 \pm 2.9$ ) to follow-up at six months (mean $=17.7 \pm 2.1$; mean difference $=1.57$ points; $P=0.262 ; 1-\beta=0.054$; $E S=0.48$ ), but regressed in their knowledge improvements from post-test (mean $=19.0 \pm 1.2$ ) to follow-up at six months (mean = $17.7 \pm 2.1$; mean difference $=-1.29$ points; $P=0.188 ; 1-\beta=0.250 ; \mathrm{ES}=0.97$ ). Both analyses were not significant meaning that neither overall knowledge recall suffered or improved at six months.

Table 3. Knowledge Assessment Scores at Pre, Post, and Follow-up

\begin{tabular}{|l|l|c|c|c|}
\hline \multicolumn{1}{|c|}{ Question } & \multicolumn{1}{|c|}{ Answer } & $\begin{array}{c}\text { Pre-Test } \\
\text { Frequency } \\
(\%, n=11)\end{array}$ & $\begin{array}{c}\text { Post-Test } \\
\text { Frequency } \\
(\%, n=11)\end{array}$ & $\begin{array}{c}\text { Follow-up } \\
\text { Frequency } \\
(\%, n=7)\end{array}$ \\
\hline Recognition & $11(100 \%)$ & $10(91 \%)$ & $7(100 \%)$ \\
\hline $\begin{array}{l}\text { What is the most accurate measure of core body } \\
\text { temperature? }\end{array}$ & Rectal thermometry & $2(18 \%)$ & $9(82 \%)$ & $5(71 \%)$ \\
\hline $\begin{array}{l}\text { Which of the following is not a main criterion for } \\
\text { diagnosis of exertional heat stroke? }\end{array}$ & Loss of sweating & $9(82 \%)$ & $9(82 \%)$ & $7(100 \%)$ \\
\hline $\begin{array}{l}\text { Which of the following is not considered a risk } \\
\text { factor for exertional heat stroke? }\end{array}$ & $\begin{array}{l}\text { A patient that has been } \\
\text { training for the past two } \\
\text { weeks prior to beginning } \\
\text { activity }\end{array}$ & & & \\
\hline $\begin{array}{l}\text { What is the key of the differential diagnosis of } \\
\text { exertional hyponatremia? }\end{array}$ & $\begin{array}{l}\text { Low serum sodium } \\
\text { concentration }\end{array}$ & $8(73 \%)$ & $9(82 \%)$ & $7(100 \%)$ \\
\hline $\begin{array}{l}\text { What is an optimal diagnostic method for } \\
\text { exertional rhabdomyolysis? }\end{array}$ & Creatine kinase & $8(73 \%)$ & $11(100 \%)$ & $7(100 \%)$ \\
\hline $\begin{array}{l}\text { A patient participates in a strenuous exercise } \\
\text { training event. During the event, the patient } \\
\text { reports muscle aches and weakness. The next } \\
\text { day the patient's morning urine sample was } \\
\text { brown. What condition do you suspect this patient } \\
\text { to have? }\end{array}$ & $\begin{array}{l}\text { Exertional } \\
\text { rhabdomyolysis }\end{array}$ & $10(91 \%)$ & $11(100 \%)$ & $7(100 \%)$ \\
\hline $\begin{array}{l}\text { How far should clinicians insert flexible } \\
\text { thermistors into the rectum for the most valid } \\
\text { estimate of core temperature? }\end{array}$ & $12-15$ cm (about 4.5-6 in) & $3(27 \%)$ & $9(82 \%)$ & $6(86 \%)$ \\
\hline $\begin{array}{l}\text { Which of the following is an environmental risk } \\
\text { factor for exertional heat illness? }\end{array}$ & $\begin{array}{l}\text { Athletic equipment } \\
\text { preventing evaporative } \\
\text { heat loss }\end{array}$ & $11(100 \%)$ & $9(82 \%)$ & $6(86 \%)$ \\
\hline $\begin{array}{l}\text { A patient presents with gastrocnemius cramping, } \\
\text { shortness of breath, and fatigue during serial } \\
\text { sprints on the volleyball court. The patient is } \\
\text { experiencing weakness, is slumped over, and } \\
\text { struggling to catch his/her breath. What condition } \\
\text { do you suspect this patient to be experiencing? }\end{array}$ & Exertional sickling & $6(64 \%)$ & $9(82 \%)$ & $3(43 \%)$ \\
\hline
\end{tabular}




\begin{tabular}{|c|c|c|c|c|}
\hline \multicolumn{5}{|l|}{ Triage } \\
\hline $\begin{array}{l}\text { Which of the following is not one of the triage } \\
\text { methods to move patients forward to resources? }\end{array}$ & $\begin{array}{l}\text { Alert, Verbal/Voice, Pain, } \\
\text { Unresponsive (AVPU) }\end{array}$ & $1(9 \%)$ & $11(100 \%)$ & $6(86 \%)$ \\
\hline $\begin{array}{l}\text { What is the goal of mass casualty incidents and } \\
\text { large-scale triage? }\end{array}$ & $\begin{array}{l}\text { To do the greatest good } \\
\text { for the greatest number } \\
\text { of causalities. }\end{array}$ & $9(82 \%)$ & $11(100 \%)$ & $6(86 \%)$ \\
\hline $\begin{array}{l}\text { Which of the following is/are included in the } \\
\text { pertinent criteria for the Simple Triage and Rapid } \\
\text { Treatment (START) strategy? }\end{array}$ & $\begin{array}{l}\text { All of the Above: } \\
\text { (Respirations, Pulse, } \\
\text { Mental Status, } \\
\text { Ambulating) }\end{array}$ & $10(91 \%)$ & $10(91 \%)$ & $5(71 \%)$ \\
\hline $\begin{array}{l}\text { When using the Simple Triage and Rapid } \\
\text { Treatment (START) strategy, which case could } \\
\text { you delay transportation (yellow)? }\end{array}$ & $\begin{array}{l}\text { The victim has serious } \\
\text { and potentially life- } \\
\text { threatening injuries that } \\
\text { are not expected to } \\
\text { deteriorate over the next } \\
\text { several hours }\end{array}$ & $3(27 \%)$ & $5(45 \%)$ & $3(43 \%)$ \\
\hline \multicolumn{5}{|l|}{ Management } \\
\hline $\begin{array}{l}\text { What recommendation should be instituted into } \\
\text { the school's emergency action plan and followed } \\
\text { by the athletic trainers when a patient collapse } \\
\text { from exertional heat illness? }\end{array}$ & $\begin{array}{l}\text { Cool first, transport } \\
\text { second }\end{array}$ & $11(100 \%)$ & $11(100 \%)$ & $7(100 \%)$ \\
\hline $\begin{array}{l}\text { What is the most efficient cooling method with a } \\
\text { patient suffering from exertional heat stroke? }\end{array}$ & Cold water immersion & $11(100 \%)$ & $11(100 \%)$ & $7(100 \%)$ \\
\hline What is the goal of cold-water immersion? & $\begin{array}{l}\text { To reduce rectal core } \\
\text { temperature to } \underline{102.5^{\circ} \mathrm{F}} \\
\text { within } \underline{30 \text { minutes of }} \\
\text { collapse }\end{array}$ & $9(82 \%)$ & $11(100 \%)$ & $6(86 \%)$ \\
\hline $\begin{array}{l}\text { Which of the following is the optimal treatment for } \\
\text { a patient suffering from exertional heat } \\
\text { exhaustion? }\end{array}$ & $\begin{array}{l}\text { Cease exercise, remove } \\
\text { from hot environment, } \\
\text { elevate legs, and provide } \\
\text { fluids }\end{array}$ & $5(45 \%)$ & $6(64 \%)$ & $4(57 \%)$ \\
\hline $\begin{array}{l}\text { A patient who is experiencing an onset of } \\
\text { exertional sickling with an oxygen concentration of } \\
94 \% \text { should receive supplemental oxygen via bag } \\
\text { valve mask at what flow rate? }\end{array}$ & $15 \mathrm{~L} / \mathrm{min}$ & $5(45 \%)$ & $10(91 \%)$ & $5(71 \%)$ \\
\hline $\begin{array}{l}\text { To prevent life-threatening complications such as } \\
\text { acute renal failure, what intervention should a } \\
\text { healthcare provider utilize for a patient suffering } \\
\text { from exertional rhabdomyolysis? }\end{array}$ & $\begin{array}{l}\text { Oral and/or intravenous } \\
\text { fluid replacement }\end{array}$ & $9(82 \%)$ & $8(73 \%)$ & $6(86 \%)$ \\
\hline $\begin{array}{l}\text { Which are the two best practices for cold water } \\
\text { immersion? }\end{array}$ & $\begin{array}{l}\text { Water temperature } \\
\text { between } 35^{\circ}-59^{\circ} \mathrm{F} \text { and } \\
\text { continuously stirring the } \\
\text { water }\end{array}$ & $7(64 \%)$ & $11(100 \%)$ & $7(100 \%)$ \\
\hline $\begin{array}{l}\text { An athletic trainer in a rural secondary school } \\
\text { does not have the budget to purchase a rectal } \\
\text { thermometer for their athletic training facility. } \\
\text { During a preseason football practice, a patient } \\
\text { presents with the signs and symptoms of } \\
\text { exertional heat stroke. What intervention is } \\
\text { supported in the literature? }\end{array}$ & $\begin{array}{l}\text { Begin cold water } \\
\text { immersion for } \\
\text { approximately } 15-20 \\
\text { minutes based on body } \\
\text { cooling rates }\end{array}$ & $11(100 \%)$ & $10(91 \%)$ & $7(100 \%)$ \\
\hline
\end{tabular}

Our participants indicated a willingness to engage in follow-up communication with the research team, including consultation on how the sessions changed their practice and educational initiatives. Two participants returned to their clinical site or hiring system 
to implement a learning experience like ours focusing on exertional sudden death. One participant implemented similar scenarios in small groups with 25 athletic trainers with varying levels of experience. He indicated:

The [Symposium] scenarios aided me in my practice by exposing me to conditions that I may not have experienced in my [previous education]. I was able to revisit some skills that I have never experienced [in real-time] and refresh skills that I use in my daily practice. The scenarios also allowed a seasoned professional as me to work with other ATs and demonstrate skills learned in the didactic portion. After the experience, I wanted to bring this similar learning experience to our staff in my work location. I believe it had a positive impact on our outreach staff. The staff of 25 athletic trainers were split into groups of 4 and had to handle multiple simulations and work together as a team. Our staff is a good mixture of seasoned and young professionals. Both learned from reach other in the simulation and in the post simulation debriefing. The [Symposium] experience was a very interesting addition to the conference; the format of actual "handson" learning and use of situational awareness was very unique for a symposium. Much more than the standard lecture or learning lab offerings, the simulation and didactic portion is a great mode to learn and experience situations before they arise in real life.

Another participant attended with a work colleague and they reached out to gain perspective and advice on how to implement simulation with their staff. After an additional video-conference meeting, they were able to implement the simulation with 7 staff members, with the help of undergraduate athletic training students serving as actors. He described the event:

We ran our program with 7 participants over 2 sessions and got a really great response from every one of them. The Athletic Training Program graciously agreed to be our actors for the scenario and even provided equipment. It was a bit of a different atmosphere than we had at [the Symposium] as the students were undergraduates rather than graduate students; however, their enthusiasm made our staff members who underwent the simulation think deeply during their evaluations, get frustrated at the "typical track practice athletic training room environment" we were able to recreate (complete with one of the kids trying to take selfies with the athletic trainers while they were doing a "cold" water immersion for the heat stroke victim. Our hope moving forward is to adapt it to possibly better suit how our program functions and pass it off to our pre-hospital care committee which would allow for additional continuing education opportunities for our staff. In the event that plan falls through and we're only left with this single simulation experience for our staff, this has already become a memorable educational experience for our staff.

A third participant framed her application of knowledge in her role as a coordinator of clinical education. She was able to share her new knowledge with preceptors:

[l am] still working on the preceptors and reminding them of the best practices and offering opportunities if they wanted to come and utilize any of our mannequins; whether it was the rectal mannequin, the airway mannequin, or even our oxygen tanks. Just giving them the opportunity because most of them have been clinicians for a while and they never had that specific training in their professional preparation. So just trying to share the information as it comes out and provide reminders. But the simulation experience did have an impact on my educational methods and the things that we do within our program as well as information to share with the students, preceptors, and faculty.

\section{DISCUSSION}

Our study was the first in the series of educational interventions to explore knowledge improvements over the long-term relative to continuing education for the practicing clinician. ${ }^{30}$ Athletic training continues to emphasize the role in immediate and emergent care with Standard 70 of the Commission on Accreditation of Athletic Training Education 2020 Standards for Accreditation of Professional Athletic Training Program that states programs must ensure that athletic training students are able to evaluate and manage patients with acute conditions, including triaging conditions that are life threatening or otherwise emergent, with specific reference to the use of rectal thermometry, and conditions related to the environment exertional sickling, rhabdomyolysis, and hyponatremia. While this may be true of newly credentialed athletic trainers, we must ensure the same standards are met for the practicing clinician as a commitment to a quality patient experience. Simulation-based learning has been widely used in professional education to prepare future healthcare professionals for these standards yet is not common in the continued development of the clinician in their lifespan. Continuing education for the practicing clinician typically involves reading peerreviewed journals and attending professional conferences but these mechanisms do not allow for practice and real-time evaluation of healthcare skills.

Although continuing education is often deemed effective, this is usually due to testing immediately following an educational intervention. ${ }^{31}$ We experienced the same phenomena whereby the participants improved significantly after the educational experience. However, the literature has demonstrated mixed results for behavioral change after an educational intervention. 
Interventions that have been effective are those that are multifaceted (use multiple modes of learning) and include a hands-on component and feedback. This was similar to our approach that used cognitive, experiential, and social constructivist theories of learning. ${ }^{34-36}$ These theoretical frameworks are meant to reinforce previously known information, engage learners in the practical application of that knowledge, and then to make meaning from that experience through vulnerable discussion. ${ }^{37}$ Single educational interventions have had a poor effect on sustained behavioral changes. ${ }^{38}$ In the previous studies about exertional heat illness and the effectiveness of an educational intervention, the researchers identified attitudes toward using best practices had significantly improved. ${ }^{24}$ However, no follow-up assessment occurred. In our investigation, we were able to assess knowledge six months after the intervention. Although performance had diminished, the differences between the post-test and follow-up were not significantly different, suggesting that time had neither improved not deteriorated their knowledge in a meaningful way.

Continuing education should not allow a learner to be a passive observer, but an active change agent in one's future clinical practice. Interactive labs and real-life situations are more effective at developing clinical practice changes. ${ }^{31,39}$ Simulations stem from the same educational theories that support interactive labs and real-life situations, and as such would likely be an effective mechanism to increase knowledge in the participant. ${ }^{40} \mathrm{In}$ order for the experience to reproduce a potential real-life scenario, the simulation must encompass the three dimensions of fidelity including equipment fidelity, environmental fidelity, and psychological fidelity. ${ }^{41}$ Psychological fidelity is concerned with the ability for the learner to perceive the simulation experience as a potential reallife encounter, thus the ability to allow themselves to be vulnerable by placing themselves in the current situation as a means for potential skill retention and transfer. ${ }^{42}$ Although we identified knowledge improvement as a result of the simulated experience combined with other modes of learning, we were unable to study participant application of knowledge in clinical practice and the effects of the intervention on patient outcomes. Very few studies have explored the effect of continuing education meetings on patient outcomes and they have found minimal change. ${ }^{31}$ Future research should compare educational intervention strategies and should hope to engage mixed-methods that would allow for us to better understand the impact of simulation on changes in clinical practice and patient outcomes.

Participants engaged in a follow-up consultation about how they were able to apply their learning into clinical practice and although we only have a few of those examples, they do suggest simulation can lead to behavior change. Specifically, the examples demonstrate a desire to improve readiness for preceptors by equipment exposure and practice. They also demonstrate a willingness, as healthcare professionals, to use similar modes of learning to assess and facilitate the implementation of best practices in their workplace. Healthcare leadership literature has been clear that the development as a leader must include the ability to engage in didactic instruction for adult learners, serving in the role of change agent, and the ability to build supportive and safe cultures. ${ }^{43}$ Simulation is an ideal mechanism to demonstrate these leadership skills and the process, whereby supervisors engage in continuing professional development and then propagate their learning that is indicative of effective leadership. Future research should explore the lived experience of learners and leaders including changes to policy, supplies, stakeholder communication, and interprofessional collaboration following professional development activities.

\section{Limitations and Future Research}

The small sample of participants is the most obvious limitation; however, few studies in healthcare have evaluated long-term effects of a simulated learning experience. We encouraged follow-up consultation to assist learners in replicating their learning experience but had also hoped to conduct formal interviews and a qualitative analysis relative to their lived experiences after the simulated learning experience. However, attrition impacted our ability to conduct a systematic evaluation of the qualitative data. Other pilot investigations relative to novel instructional strategies like problem-based and simulation-based learning in practicing clinicians have included studies ranging from 10 to 50 learners. ${ }^{44-49}$

The research study provided pilot data to support that simulation-based learning was effective in a repeated measures design, but long-term knowledge gains may not be supported. We did not identify if participants experienced any similar multi-patient trauma events or had to recognize and treat any of the exertional sudden death conditions in their clinical practice. In addition, as is native to large-group simulation, each learner had a different learning experience. For instance, some of the participants were not involved in measuring core body temperature or selecting cold water immersion as the preferred treatment for the patient experiencing exertional heat stroke. Additionally, the continuing professional development literature has suggested that single learning events are ineffective at implementing behavior change. Mechanisms that focused on the reinforcement of these concepts, for instance, through follow-up e-mail notifications (e.g. infographics, tips for practice) or through the application of the concepts in clinical practice may have resulted in improved knowledge or at least a lower rate of decay. Future research should enroll participants in longitudinal studies to evaluate the effect of periodic reinforcement (multiple interventions) during continuing professional development.

\section{CONCLUSION}

(c) The Internet Journal of Allied Health Sciences and Practice, 2020 
Our findings suggest that a multi-modal educational intervention that highlighted a simulated-learning experience with debrief was effective at improving knowledge immediately following the session. Although not significantly decreased, learners demonstrated diminished knowledge at the six-month follow-up. Our findings are consistent with other continuing professional development literature that suggests multiple modes of instruction are most effective at improving knowledge. Our study is the only one, to our knowledge, that has looked at the effects of simulation-based instruction in practicing clinicians longitudinally. Although we experienced a small sample size and attrition, our findings are promising. As we consider our findings relative to continuing professional development, simulation could allow athletic training healthcare professionals to engage in didactic instruction for adult learners, serve as a change agent, and build supportive and safe cultures in their work environment. With further study, it is possible that we could confirm that simulation-based instruction, facilitated by healthcare leaders or managers, can improve, and maintain knowledge, as well as impact patient outcomes. Continuing professional development should promote continued competence of skills while developing and enhancing clinical judgment. The use of simulation-based learning, while more time consuming, aims to do each of these in an active process for the adult learner.

\section{REFERENCES}

1. Kerr ZY, Register-Mihalik JK, Pryor RR, et al. The association between mandated preseason heat acclimatization guidelines and exertional heat illness during preseason high school American football practices. Environ Health Perspect. 2019;127(4):047003.

2. Yeargin SW, Dompier TP, Casa DJ, Hirschhorn RM, Kerr ZY. Epidemiology of exertional heat illnesses in National Collegiate Athletic Association athletes during the 2009-2010 through 2014-2015 academic years. J Athl Train. 2019;54(1):55-63.

3. Casa DJ, DeMartini JK, Bergeron MF, et al. National Athletic Trainers' Association position statement: exertional heat illnesses. J Athl Train. 2015;50(9):986-1000.

4. Casa DJ, Guskiewicz KM, Anderson SA, et al. National Athletic Trainers' Association position statement: preventing sudden death in sports. J Athl Train. 2012;47(1):96-118.

5. $\quad$ NewsCore. Rare muscle disorder sidelines players on Ohio State women's lacrosse team. March 12, 2012; https://www.foxnews.com/health/rare-muscle-disorder-sidelines-players-on-ohio-state-womens-lacrosse-team. Accessed August 19, 2019.

6. Heinz F. 8 Texas Woman's University athletes hospitalized for exertional rhabdomyolysis. August 26, 2016; https://www.nbcdfw.com/news/local/8-Texas-Womans-University-Athletes-Hospitalized-for-Exertional-Rhabdomyolysis391423311.html. Accessed August 11, 2019.

7. $\quad$ King A. 6 Ohio State women's track team members hospitalized, released. September 9, 2014; https://www.thelantern.com/2014/09/6-ohio-state-womens-track-team-members-hospitalized-released/. Accessed August 11, 2019.

8. $\quad$ Adame T. Six Butler softball players treated for skeletal muscle condition after workouts. August 17, 2015; https://www.kansas.com/sports/college/state-college-sports/article31327925.html. Accessed August 11, 2019.

9. McKewon S. Two Nebraska football players hospitalized, treated after offseason workout. January 30, 2018; https://www.omaha.com/huskers/football/two-nebraska-football-players-hospitalized-treated-after-offseasonworkout/article d5929674-53a7-5d90-803e-6b4e9205ee60.html. Accessed August 11, 2019.

10. $\quad$ Parenteau D. lowa football: What landed 13 players in the hospital? January 27, 2011; https://bleacherreport.com/articles/586596-iowa-football-what-landed-13-players-in-the-hospital. Accessed August 11, 2019.

11. Greif A. Multiple Oregon Ducks football players hospitalized after grueling workouts. January 16, 2017; https://www.oregonlive.com/ducks/2017/01/oregon_ducks_workouts_hospital.html. Accessed August 11, 2019.

12. $\quad$ Robertson-Steel I. Evolution of triage systems. Emergency Medicine Journal. 2006;23(2):154-155.

13. Iserson KV, Moskop JC. Triage in medicine, part I: concept, history, and types. Annals of emergency medicine. 2007;49(3):275-281.

14. Mazerolle SM, Scruggs IC, Casa DJ, et al. Current knowledge, attitudes, and practices of certified athletic trainers regarding recognition and treatment of exertional heat stroke. J Athl Train. 2010;45(2):170-180.

15. Eberman LE, Tripp BL. Effect of performance feedback on perceived knowledge and likelihood to pursue continuing education. Athl Train Educ J. 2011;6(2):69-75.

16. Mazerolle SM, Pagnotta KD, Casa DJ, Armstrong L, Maresh C. Professional preparation regarding the recognition and treatment of exertional heat stroke: the student perspective. Athl Train Educ J. 2011;6(4):182-193.

17. Kerr ZY, Marshall SW, Comstock RD, Casa DJ. Exertional heat stroke management strategies in United States high school football. Am J Sport Med. 2014;42(1):70-77. 
18. Mazerolle SM, Pinkus DE, Casa DJ, et al. Evidence-based medicine and the recognition and treatment of exertional heat stroke, part II: a perspective from the clinical athletic trainer. J Athl Train. 2011.

19. National Athletic Trainers' Association. Athletic Training Education Competencies. In. 5th ed2011.

20. Commission on Accreditation of Athletic Training Education. Standards for the Accreditation of Professional Athletic Training Programs. In:2012.

21. Jenkins JL, McCarthy ML, Sauer LM, et al. Mass-casualty triage: Time for an evidence-based approach. Prehosp Disaster Med. 2008;23(1):3-8.

22. Lateef F. Simulation-based learning: Just like the real thing. J Emerg Trauma Shock. 2010;3(4):348.

23. Gaba DM. The future vision of simulation in health care. BMJ Quality \& Safety. 2004;13(suppl 1):i2-i10.

24. Schellhase KC, Plant J, Mazerolle SM. Athletic trainers' attitudes and perceptions regarding exertional heat stroke before and after an educational intervention. Athl Train Educ J. 2017;12(3):179-187.

25. Cleary MA, Nottingham SL, Kasamatsu TM, Bennett JP. Using a continuing education workshop to facilitate implementation of evidence-based practices for recognition and treatment of exertional heat stroke in secondary school athletic trainers. Athl Train Sports Health Care. 2016;8(3):100-111.

26. INACSL Standards Committee. INACSL standards of best practice: SimulationSM simulation design. Clin Simul Nurs. 2016;12:S5-S12.

27. University of lowa. Report of the Special Presidential Committee to Investigate the January 2011 Hospitalization of University of lowa Football Players. Available at http://www.iowaregents.edu/media/cms/finalreportonrhabdoincidentpdf1A6655AB.pdf. Accessed 4/15/2017.

28. Walker S, Armstrong KJ, Jarriel AJ. Standardized patients, part 4: Training. Int J Athl Ther Train. 2011;16(5):29-33.

29. Dreifuerst KT. Using debriefing for meaningful learning to foster development of clinical reasoning in simulation. $J$ Nurs Educ. 2012;51(6):326-333.

30. Doherty-Restrepo JL, Hughes BJ, Del Rossi G, Pitney WA. Evaluation models for continuing education program efficacy: how does athletic training continuing education measure up? Athl Train Educ J. 2009;4(3):117-124.

31. Forsetlund L, Bjørndal A, Rashidian A, et al. Continuing education meetings and workshops: Effects on professional practice and health care outcomes. Cochrane Database Syst Rev. 2009(2).

32. Bero LA, Grilli R, Grimshaw JM, Harvey E, Oxman AD, Thomson MA. Closing the gap between research and practice: An overview of systematic reviews of interventions to promote the implementation of research findings. Cochrane Database Syst Rev. 1998;317(7156):465-468.

33. Wensing M, van der Weijden T, Grol R. Implementing guidelines and innovations in general practice: which interventions are effective? Br J Gen Pract. 1998;48(427):991-997.

34. Piaget J. Part I: Cognitive development in children: Piaget development and learning. J Res Sci Teach. 1964;2(3):176186.

35. Schellhase KC. Kolb's experiential learning theory in athletic training education: a literature review. Athl Train Educ J. 2006;1(2):18-27.

36. Thomas A, Menon A, Boruff J, Rodriguez AM, Ahmed S. Applications of social constructivist learning theories in knowledge translation for healthcare professionals: a scoping review. J Implementation Science. 2014;9(1):54.

37. Bradley P, Postlethwaite K. Simulation in clinical learning. Med Educ. 2003;37:1-5.

38. Grimshaw J, Thomas R, MacLennan G, et al. Effectiveness and efficiency of guideline dissemination and implementation strategies. Health Technol Asses. 2004.

39. Samdperil G. Emerging trends for continuing education in athletic training. 2012.

40. Brender E, Burke A, Glass RM. Standardized patients. JAMA. 2005;294(9):1172-1172.

41. Beaubien JM, Baker DP. The use of simulation for training teamwork skills in health care: How low can you go? BMJ Qual Saf. 2004;13(suppl 1):i51-i56.

42. Kozlowski SW, DeShon RP. A psychological fidelity approach to simulation-based training: Theory, research and principles. Scaled worlds: Development, validation, and applications. 2004:75-99.

43. Sonnino RE. Health care leadership development and training: progress and pitfalls. Journal of healthcare leadership. 2016;8:19.

44. Smits P, Verbeek J, De Buisonje C. Problem based learning in continuing medical education: a review of controlled evaluation studies. BMJ. 2002;324(7330):153-156.

45. Kim JH, Shin JS. Effects of an online problem-based learning program on sexual health care competencies among oncology nurses: a pilot study. Journal of Continuing Education in Nursing. 2014;45(9):393-401.

46. Radhakrishnan K, Roche JP, Cunningham H. Measuring clinical practice parameters with human patient simulation: A pilot study. International Journal of Nursing Education Scholarship. 2007;4(1). 
47. Reznek M, Smith-Coggins R, Howard S, et al. Emergency Medicine Crisis Resource Management (EMCRM): Pilot study of a simulation-based crisis management course for emergency medicine. Academic Emergency Medicine. 2003;10(4):386-389.

48. Kim J, Neilipovitz D, Cardinal P, Chiu M, Clinch J. A pilot study using high-fidelity simulation to formally evaluate performance in the resuscitation of critically ill patients: The University of Ottawa Critical Care Medicine, High-Fidelity Simulation, and Crisis Resource Management I Study. Critical care medicine. 2006;34(8):2167-2174.

49. Bong CL, Lightdale JR, Fredette ME, Weinstock P. Effects of simulation versus traditional tutorial-based training on physiologic stress levels among clinicians: a pilot study. Simulation in Healthcare. 2010;5(5):272-278. 